\title{
THE IMPORTANCE OF VIRTUAL TECHNOLOGIES IN EDUCATION
}

\author{
Ejup Rustemi ${ }^{1 *}$ Mefail Tahiri $^{2}$ \\ ${ }^{1}$ University of Tetova, North Macedonia \\ ${ }^{2}$ University of Tetova, North Macedonia \\ *ejup.rustemi@yahoo.com
}

\begin{abstract}
Students with their school bags are walking, smiling, and moving forward with the goal to reach the school. They enter school, sit on their chairs waiting for their teacher, who enters with books in his hands ready for the class to begin. These scenes seem from a long time ago, especially in the schools of North Macedonia where we live. The pandemic that the world is facing from 2020 has changed the way how we learn and educate our students. Distance learning has become the main way of teaching and learning, thus making us question our school methodologies and the way we provide and acquire knowledge. Digital platforms have become the new way teachers and students communicate. It is important to mention that there are schools that use a combination of physical and digital learning, but the important issue here is that schools may be going through a very important change, which will certainly be affected from how long the pandemic will last, but which will leave its mark even long after it ends. These are the aspects that this paper we deal in providing information about different platforms and how each one of them has affected the learning and teaching process, whether it is in our region or in the world as a whole. Things, of course, haven't been so smooth, because it seems that the world wasn't prepared for such a drastic change in this field, therefore education systems had to face many hurdles in order to find a middle ground to make the transition as successful as possible. Some countries have had better results, some not so much, but one thing is for certain, Tech companies have given us a large number of alternatives of which some may have suited best in one school, while some in another. Regarding this important transition, schools have faced technical and training problems, where some have lacked any proper knowledge about the digital platforms that exist for this purpose, while others in addition to that, have lacked adequate computer devices to make an effective teaching/learning process. We will try to explain why parts of the world weren't properly prepared for times like these and if there is some hope that there is a brighter future for the educational systems to provide the needed learning quality for the generations to come. But he most important thing is whether we as human beings who are in constant need for knowledge, are learning a lesson from these hard times and are preparing ourselves for possible similar times like these in the future. In one way we need to reflect on what went wrong and, at the same time, make important steps to improve tomorrow.
\end{abstract}

Keywords: virtual classroom, distance learning, digital learning platforms.

\section{INTRODUCTION}

Education is one of the most important pillars of any society; if it fails to provide the needed results the whole society is in trouble. As members of the human race, we all need to consider the fact we must keep the educational system going, no matter the time and hurdles. The Covid 19 pandemic has put this system in a great test, and different countries have had different approach in dealing with this occurrence. What is important in our paper is the fact that big tech companies such as Microsoft and Google have come up with various platforms in helping schools and universities face these difficult times. But we must mention that, schools have used these technologies way before the pandemic, therefore we need to emphasize the importance of learning to use these platforms in our classes no matter the conditions, because they can be extremely helpful in every classroom, pandemic or not. This is to emphasize the ways virtual technologies can be a useful asset in improving the way we learn and teach. These tools can help expand on other common and conventional methods, thus making a more effective classroom in all levels of education. 


\section{VIRTUAL VS TRADITIONAL}

Humans have always strived to learn. Previous learning methodologies have been of various kinds, but mostly focused on teacher centered style of teaching. Nowadays things have started to change and the classroom has become a place where the student is the main focus.

Student-centered classrooms have become a reality and virtual technologies are helping shape this environment in such ways that it has facilitated the way teacher interacts with students in the classroom and more importantly in remote learning environments. These technologies provide the means for faster and more accurate assessment, and what is even more important, they provide unique ways of explaining the lessons in a practical way (Sirkko, R., Takala, M., \& Wickman, K. ,2018).

If we are to consider the recent Covid 19 pandemic, where many schools around the world have begun using virtual classrooms and distance learning, their importance has become more pronounced. If we take for example the assessment part of the problem, we can testify that in the University of Tetova we have successfully used the exam.net platform for all faculties and in that way, we have never interrupted the learning and exam process.

The platform has provided us with enough tools, especially when we have combined it with other platforms such as Google Meet, to have a qualitative teaching and learning approach. It is clear that in the beginning we had some issues, as with any other platform that is established for the first time, but with proper training and experience things have moved very smoothly.

Fig. 1 Virtual exam platform

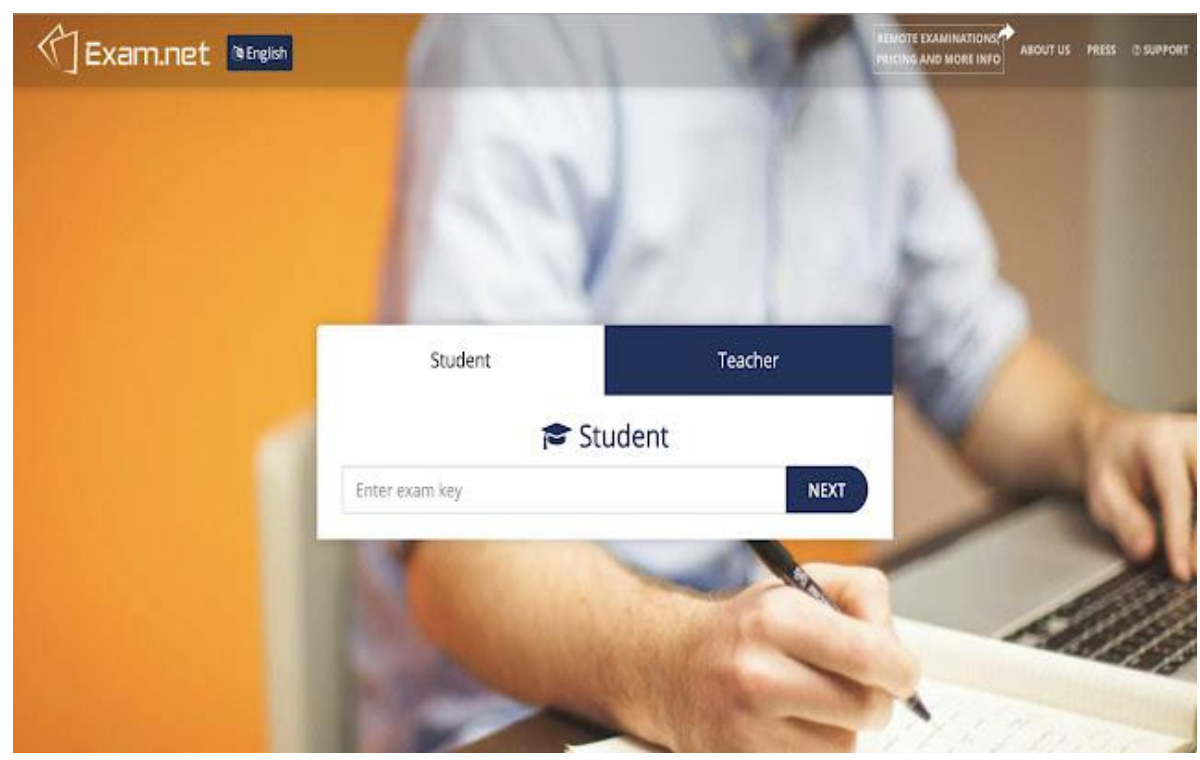

\section{IMPORTANCE OF INTERACTIVITY}

As we mentioned before, teacher interaction with the students is of utmost importance, therefore using digital platforms to move the process forward is of special importance. We should mention one other thing which we believe to be very important regarding this aspect of collaboration software or virtual classroom; many of these platforms were never meant for teaching purpose, although using them as such has never been an issue, but we should keep in mind that such platforms have been first and foremost made for business meeting or chatting rooms for social platform interaction (Suorsa, 2017).

One such platform that has gained widespread usage is Microsoft Teams. This platform was initially made for busines teams so they can communicate when working from distance. Teams is one of the if not the most advanced platforms we can use for learning purpose. It provides video and audio communication, file sharing, chatting option, meeting schedules, and what makes it different from other platforms that we will mention next, it has the ability to be further advanced with a lot of plugins from other platforms and in such a way making it a great tool for teacher and students to use. 
Fig. 2 Microsoft Teams

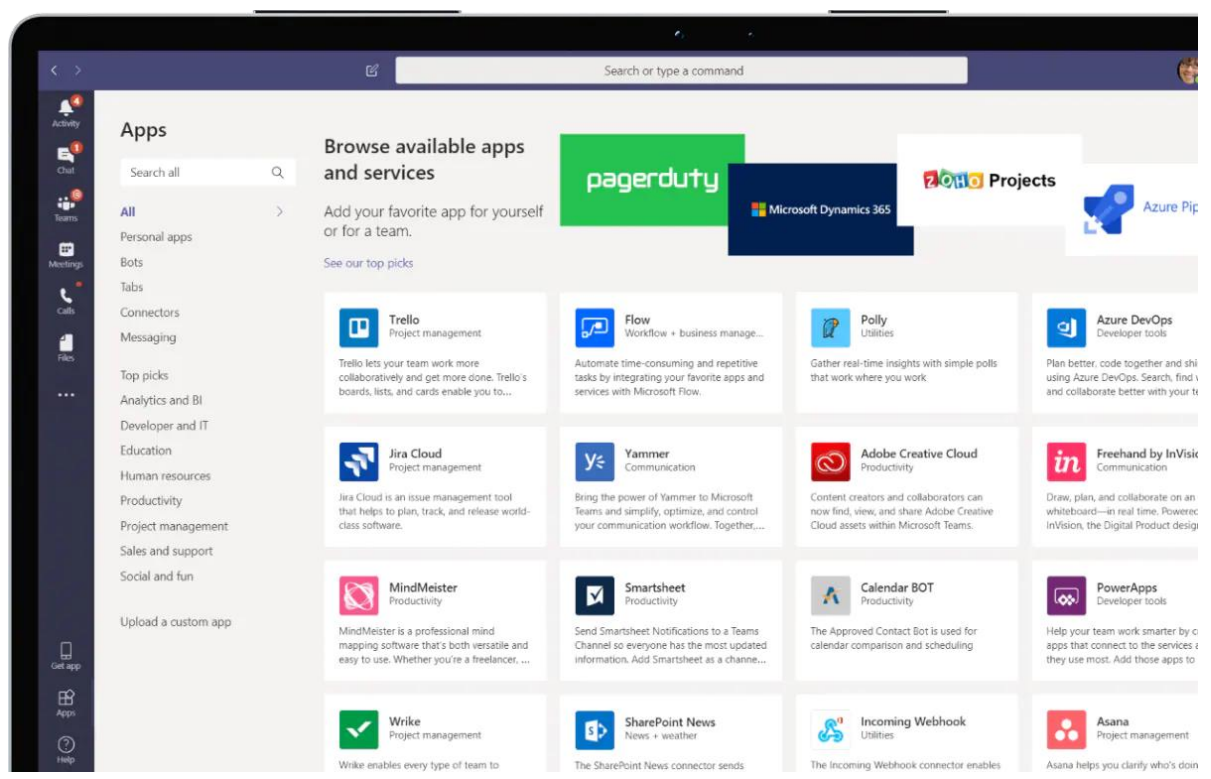

Another platform that has gained a lot of attention is Google Meet. Although not as advanced as Microsoft Teams, when combined with other platforms, Google Meet can be very helpful to move the learning process forward. This is the platform that we have used at the University of Tetova and it has provided us with a very easy and invaluable tool for communication and interaction.

Fig. 3 Goggle Meet

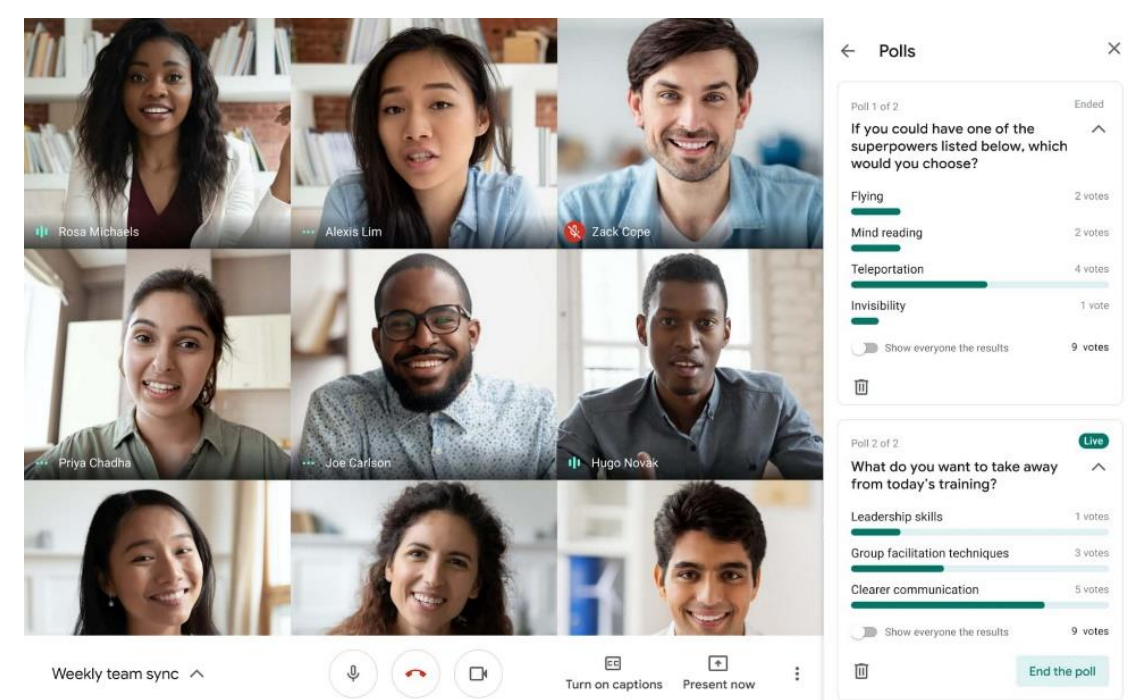

Zoom is probably the most famous distance collaboration software. Many schools and universities around the world, North Macedonia included, have used Zoom for virtual classroom environment for the simple fact that it is easier to use than other platforms. Compared to other platforms, Zoom, in its free version offers meeting up to 40 minutes, whereas Google Meet has been free, at least for the time the Covid pandemic is present, while on the other hand, Microsoft Teams does not have such limitations as meeting duration, although the paid version has some more advanced features. 


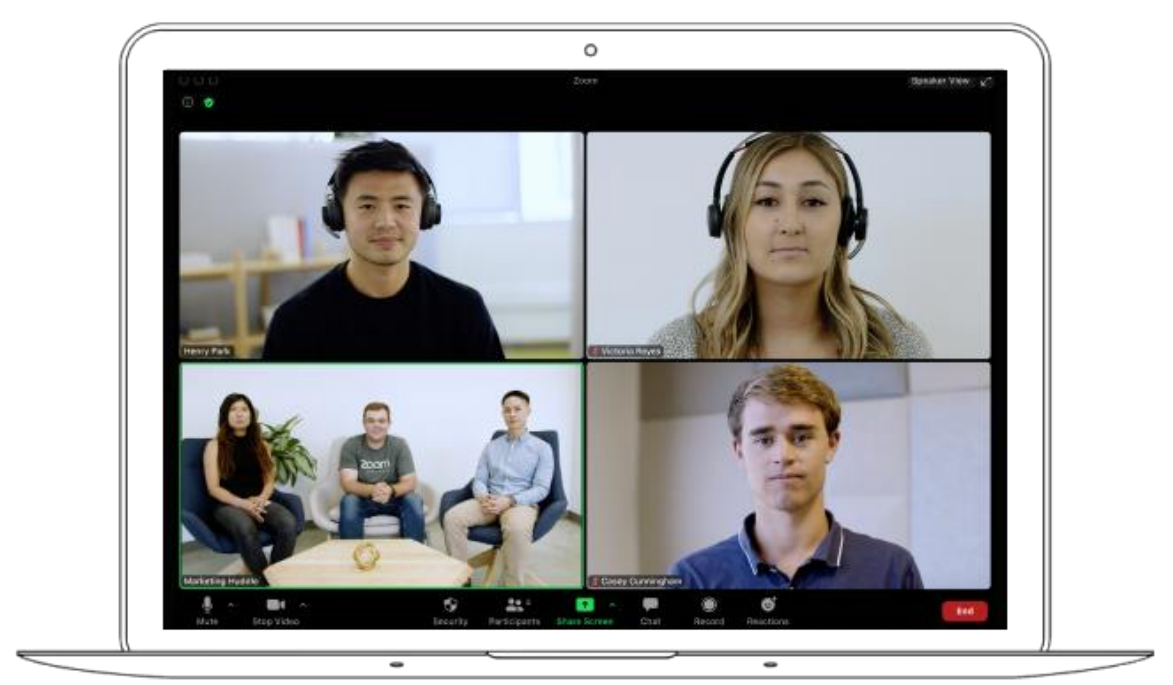

\section{QUALITY ALWAYS COMES FIRST}

No matter the platform we choose, we should keep in mind that each one of them is provided by highly established IT companies, therefore, the only thing that we should keep in mind is to make the learning process as qualitative as possible. Quality will bring success, thus finding the tools which suit us best is important to make lessons more practical and avoid any possible abstraction. Nowadays, many schools use digital whiteboards to write tasks and examples because through them we can make better presentations compared to traditional blackboards (Tan, S. C., \& Lee, A. V. Y., 2018).

\section{CONCLUSION}

Based on what we have written in this paper if there is one thing that is certain, it has to be the fact that education must continue, no matter how we plan to do it. New generations need to learn, children must learn to read and write; students must study and schools must operate. Things change, there may be times when everything goes smoothly, but there are also times when we may face things never seen before, therefore we must be prepared to manage our lives in general and our education system in specific. Virtual technologies can be a vessel on which education can move forward no matter the times and obstacles. Yes, we know that not always the results can be as we want them, but it is important that we learn and improve by each passing day. Thankfully, opportunities are many and alternatives are enough we believe, but platforms are insignificant if we are not ready to use them, or in a more serious note, if we don't want to be able to use them, and this where things become problematic, because in such cases we always try to put the blame on other individuals or institutions by masking our unwillingness to make the needed step towards a better tomorrow.

\section{References and Bibliography}

Damsa, C., \& Muukkonen, H. (2020). Conceptualising pedagogical designs for learning through object- oriented collaboration in higher education. Research Papers in Education, 35(1), 82-104. https://doi. org/10.1080/02671 522.2019.1677751.

Evans-Lacko, S., Takizawa, R., Brimblecombe, N., King, D., Knapp, M., Maughan, B., \& Arseneault, L. (2017). Childhood bullying victimization is associated with use of mental health services over five decades: A longitudinal nationally representative 
$\begin{array}{lllll}\text { cohort study. } \quad \text { Psychological } & \text { Medicine, 47(1), } 127-\end{array}$ https://doi.org/10.1017/S0033291716001719.

Flor, M., Yoon, S. Y., Hao, J., Liu, L., von Davier, A. A. (2016). Automated classification of collaborative problem solving interactions in simulated science tasks. In Proceedings of the 11th workshop on innovative use of NLP for building educational applications, Stroudsburg, PA, USA: Association for Computational Linguistics, 31-41.

García-García, C., Chulvi, V., \& Royo, M. (2017). Knowledge generation for enhancing design creativity through co-creative virtual learning communities. Thinking Skills and Creativity, 24, 12-19. https://doi. org/10.1016/j.tsc.2017.02.009.

Goepel, J. (2009). Constructing the individual education plan: Confusion or collaboration? Support for Learning, 24(3), 126-132.

Lakkala, M., Toom, A., Ilomäki, L., \& Muukkonen, H. (2015). Re-designing university courses to support collaborative knowledge creation practices. Australasian Journal of Educational Technology, 31(5), 521-536

Säljö, R. (2010). Digital tools and challenges to institutional traditions of learning: Technologies, social memory and the performative nature of learning. Journal of Computer Assisted Learning, 26, 53-64.

Sirkko, R., Takala, M., \& Wickman, K. (2018). Co-teaching in northern rural Finnish schools. Education in the North, 25(1-2), 217-237.

Suorsa, A. R. (2017). Knowledge creation and play: A phenomenological study within a multiprofessional and multi-organizational community. Journal of Documentation, 73(6), 1167-1191. https://doi. org/10.1108/JD-11-2016-0141.

Tan, S. C., \& Lee, A. V. Y. (2018). Online learning communities in K-12 settings. In J. Voogt, G. Knezek, R.Christensen, \& K. W. Lai (Eds.), Handbook of information Technology in Primary and Secondary Education (pp. 1-21). Cham: Springer International Handbooks of Education. Springer. https://doi. org/10.1007/978-3-319-53803-7_48-1. 